\title{
Effect of maternal deprivation on the gonadotrophin-releasing hormone (GnRH) and GnRH-associated peptide neurobiology in lambs during the transition from infancy to prepuberty
}

\author{
Marta Wańkowska, Jolanta Polkowska
}

Department of Endocrinology, The Kielanowski Institute of Animal Physiology and Nutrition, Polish Academy of Sciences, Jabłonna, Poland

\begin{abstract}
Using morphological criteria we describe the effect of maternal deprivation on the gonadotrophin-releasing hormone (GnRH) and GnRH-associated peptide (GAP) of the GnRH prohormone (proGnRH) in the preoptic area (POA)-hypothalamus during the weaning period. The immunohistochemical GnRH- and GAP-neuroanatomy was investigated in female 12-week-old weanling and maternally deprived lambs and 15-week-old weaned lambs. The GnRH-immunoreactive (ir) nerve elements in the POA were more numerous in weanling and weaned lambs in comparison with maternally deprived lambs, whereas the nerve elements ir for GAP were numerous in weanlings and scarce in remaining lambs. In the hypothalamus, GnRH-ir fibers were more numerous in weaned lambs in comparison with others. Immunoreactive GnRH in the median eminence was scarce in weanlings and comparable greater in maternally deprived and weaned lambs. In contrast to ir GnRH, the GAP-ir fibers and nerve terminals in the hypothalamus and median eminence were numerous in weanlings and maternally deprived lambs and scarce in weaned lambs. In conclusion, maternal deprivation affects the intraneuronal locations involved in the maturation of GnRH from proGnRH in the POA-hypothalamus of weanlings. The described effect involves the increase in the GnRH posttranslational processing and terminal accumulation in the median eminence, which reflects the maturational increase from the low infantile terminal storage to the high prepubertal one.
\end{abstract}

Key words: GnRH, GnRH-associated peptide, neurobiology, maternal deprivation, weaning

\section{Introduction}

Gonadotrophin hormone-releasing hormone ( $\mathrm{GnRH})$ is the primary hypophysiotrophic messenger involved in the activation of pituitary gonadotrophins during sexual maturation [1-4]. It is produced by a loose continuum of neurons in the medial ventral preoptic-hypothalamic region of the brain that project to the portal system connecting the brain to the pituitary. The sequence of the prohormone for GnRH (proGnRH) is preceded by a signal peptide of 23 amino acids in the precursor molecule (preproGnRH), includes the GnRH decapeptide followed by a 3 amino acid processing site and the final 56 amino acid residue designated GnRH-

Correspondence: M. Wańkowska, Dept. of Endocrinology, The Kielanowski Institute of Animal Physiology and Nutrition, Polish Academy of Sciences, Instytucka 3, 05-110 Jabłonna, Poland; tel.: (+4822) 7824037 315, fax.: (+4822) 7742038,

e-mail:m.wankowska@ifzz.pan.pl associated peptide (GAP) [5,6]. In rats, sheep and primates ir GAP has been co-localized with GnRH in the median eminence and is presumably secreted into portal blood simultaneously with GnRH [7-10]. Changes in the endocrine environment similarly affect both GnRH and GAP secretion in adult rats [10].

We have recently found that the neuroendocrine transition from infancy to prepuberty changes the tempo of $\mathrm{GnRH}$ maturation from proGnRH and GnRH-GAP neuroanatomy from the infantile to the pubertal pattern, which allows the inauguration of the breeding season in sheep [11]. The natural mechanisms of transition from the infantile to prepubertal period of postnatal ontogeny include the psychosomatic effects of weaning. In the sheep, the weaning period lasts until approximately 15 weeks of age according to the period of the digestive system development. The weaning period is thought to be not static but shift for the postnatal development of gonadotrophic functions 
[11]. In this regard, the neuroenocrine infantile/prepubertal transition corresponds with the period when growth maturation is ending and sexual maturation is beginning, as was previously described for sheep $[12,13]$. Weaning is associated with a rupture of the mammalian mother-young social bond and, if abrupt, results in the stress of maternal deprivation, i.e. psychoemotional and in consequence physiological disturbances of homeostasis [14]. The psychosomatic state evoked by maternal deprivation affects the hypothalamo-pituitary-adrenal (HPA) axis in the infantile mammal, causing the stress-like endocrine response of pituitary [14-17]. In lambs during weaning, the increase in corticotrophin-releasing hormone release from the nerve terminals in the median eminence to the pituitary portal circulation is followed by hypertrophy and hyperplasia of corticotrophs in reply to the prolonged psychoemotional challenge to homeostasis. In consequence, the stressful disruption of social interactions between young and mother affects the intrapituitary mechanisms underlying the secretion of gonadotrophic hormones during the transition from the infantile to the juvenile period of ontogeny in the lamb [14].

This immunohistochemical (IHC) investigation should resolve the problem of the effect of maternal deprivation on the intraneuronal locations involved in the posttranslational processing of GnRH in the preoptic area (POA)-hypothalamus during the transition period between infancy and prepuberty in lambs.

\section{Materials and methods}

Animals. Subjects were Polish Merino female sheep born at the beginning of July at the Bieganowo Farm (Poland). The investigation was performed during a period of shortening days after summer solstice in lighting and temperature conditions present at $52^{\circ} \mathrm{N}$ latitude and $21^{\circ} \mathrm{E}$ longitude. Lambs were left to graze with dams in a pasture for 12 weeks after parturition. Ovary-intact lambs were divided randomly into two 12-week-old groups, weanling $(n=3)$ and maternally deprived $(\mathrm{n}=3)$ and one 15 -week-old group beyond the time of weaning ( 2 weeks after weaning, $n=4$ ). The 12-weekold lambs were independent of their mothers in respect of feeding. Weanling lambs grazed with flock in a pasture and suckled their mothers approximately twice per 24 hours. Maternally deprived lambs were separated from dams and kept in partial isolation from the herd within the fenced part of the pasture for a period of $72 \mathrm{~h}$. The psychobiological details and conditions of this isolation are described more precisely in our previous study [14]. Briefly, maternal deprivation was the social contact with other lambs deprived of maternal stimulation and inspected audiovisual and olfactory contact with their herd but not with their dams. Then, lambs were anesthetized with an intravenous injection of pentobarbitone sodium (20 mg/kg; Biochemie GmbH, Kundl, Austria), exsanguinated and decapitated. Twelve-week-old lambs were dissected in the local licensed slaughterhouse at Bieganowo Farm. The lambs from the group beyond the time of weaning were transported to the Institute of Animal Physiology and Nutrition (Jabłonna, Poland) shortly after their weaning at 12 weeks of age. The lambs from the group beyond the time of weaning were penned indoors and then were dissected in a local licensed slaughterhouse. All procedures were approved by the $3^{\text {rd }}$ Local Ethics Committee in Warsaw (No. of opinion 12/2001), according to the Polish Law for the Care and Use of Animals (2 August 1997).

Tissue preparation and immunohistochemistry. Immediately after decapitation, the brains were perfused via the carotid arteries with $1000 \mathrm{ml} 0.1 \mathrm{M}$ phosphate buffered saline (PBS; Sigma, St Louis, USA) and subsequently with $1500 \mathrm{ml} 0.1 \mathrm{M}$ PBS containing 4\% (w/v) paraformaldehyde (Sigma-Aldrich, Seelze, Germany) and 15\% saturated picric acid (MERCK, Darmstadt, Germany) solution (w/v), pH 7.4. Blocks of a selected POA-hypothalamus area were removed from the cranium and postfixed by immersion in this same fixative at $4{ }^{\circ} \mathrm{C}$ for $72 \mathrm{~h}$. Tissue blocks were cryoprotected in $20 \%$ sucrose solution in $0.1 \mathrm{M} \mathrm{PBS}$ at $4^{\circ} \mathrm{C}$, frozen at $-10^{\circ} \mathrm{C}$ and sectioned in coronal planes between the septum and mammillary bodies into $10 \mu \mathrm{m}$ sections.

The GnRH and GAP immunodetection was performed on freefloating sections with the peroxidase labelled antibody method using a previously described IHC procedure [14]. The sections were incubated with primary sera, anti-sheep(2-10) GnRH No. 1900 diluted 1:1000 and anti-rat GAP No. M-1 diluted 1:5000 for 8 days at $4^{\circ} \mathrm{C}$. The rabbit anti-sheep GnRH serum was prepared at the Institut National de la Recherche Agronomique (INRA, Nouzilly, France). Methodological details of their preparation and their specificity were described by Barry et al. [18] and Dubois and Barry [19]. The rabbit anti-rat GAP serum No. M1 was kindly provided by Dr M.D. Culler (IPSEN, Milford, Massachusetts, USA); details of the preparation and specifity were described by Culler and Negro-Vilar [20]. The midportion of the GAP peptide sequence, against which the used anti-GAP serum was generated [20], can help to distinguish between GnRH and the remaining portion of its prohormone [21]. After the incubation with primary antibodies, sections were incubated for $2 \mathrm{~h}$ with the secondary antibody (sheep anti-rabbit Ig [H + L] labelled with peroxidase; BIORAD, Steenvoorde, France) diluted $1: 40$ in $0.1 \%$ normal lamb serum in $0.01 \mathrm{M}$ PBS. Sections were additionally stained by the intensification method of Liposits et al. [22].

For control staining, the primary antiserum was replaced with this same dilution of rabbit serum and the anti-hormone serum was inhibited with its homologous antigen. The preabsorption of the antisera with increasing concentrations (500 ng - 50 $\mu \mathrm{g}$ ) of synthetic GnRH (UCB, Belgium) or synthetic GAP (Peninsula Laboratories, USA) per $1 \mathrm{ml}$ of the GnRH or GAP antiserum was performed. The immunoreaction decreased according to the gradual increase in concentrations of GnRH or GAP. The $10 \mu \mathrm{g} / \mathrm{ml}$ of peptide totally abolished the immunostaining. The cross-absorption of the GnRH antiserum with GAP peptide or the GAP antiserum with GnRH peptide did not affect the quality and distribution of the immunostaining, what excludes potential cross-reactivity. The antisera and antigens were mixed in $0.1 \%$ normal lamb serum in $0.01 \mathrm{M}$ PBS, preincubated for $24 \mathrm{~h}$ at $4{ }^{\circ} \mathrm{C}$ and then used for the IHC staining instead of the primary antibody (data not shown).

Image and statistical analyses. A type 104 Nikon projection microscope (Nikon Corporation, Yokohama, Japan), Panasonic KR222 camera (Matsushita Electric Industrial Co, Osaka, Japan) and "Lucia" image analysis computer system version 3.51ab (Laboratory Imaging Ltd, Prague, Czech Republic) were used for histological analyses of ir GnRH or GAP in the POA-hypothalamus. Anatomical structures were identified using the atlas of the sheep brain developed by Welento et al. [23]. Qualitative and quantitative analyses of neurons distribution and number of perikarya or the area fraction for the immunoproduct in fiber varicosities and nerve terminals were conducted in (i) every eighth section through the medial POA from its rostral aspects near the diagonal band of broca (DBB) to caudal aspects in the vicinity of the rostral aspect of the anterior hypothalamic nucleus (10 sections per animal), (ii) every tenth section through the anterior hypothalamic area (AHA) on both sides of the third ventricle of the brain (10 sections per ani- 


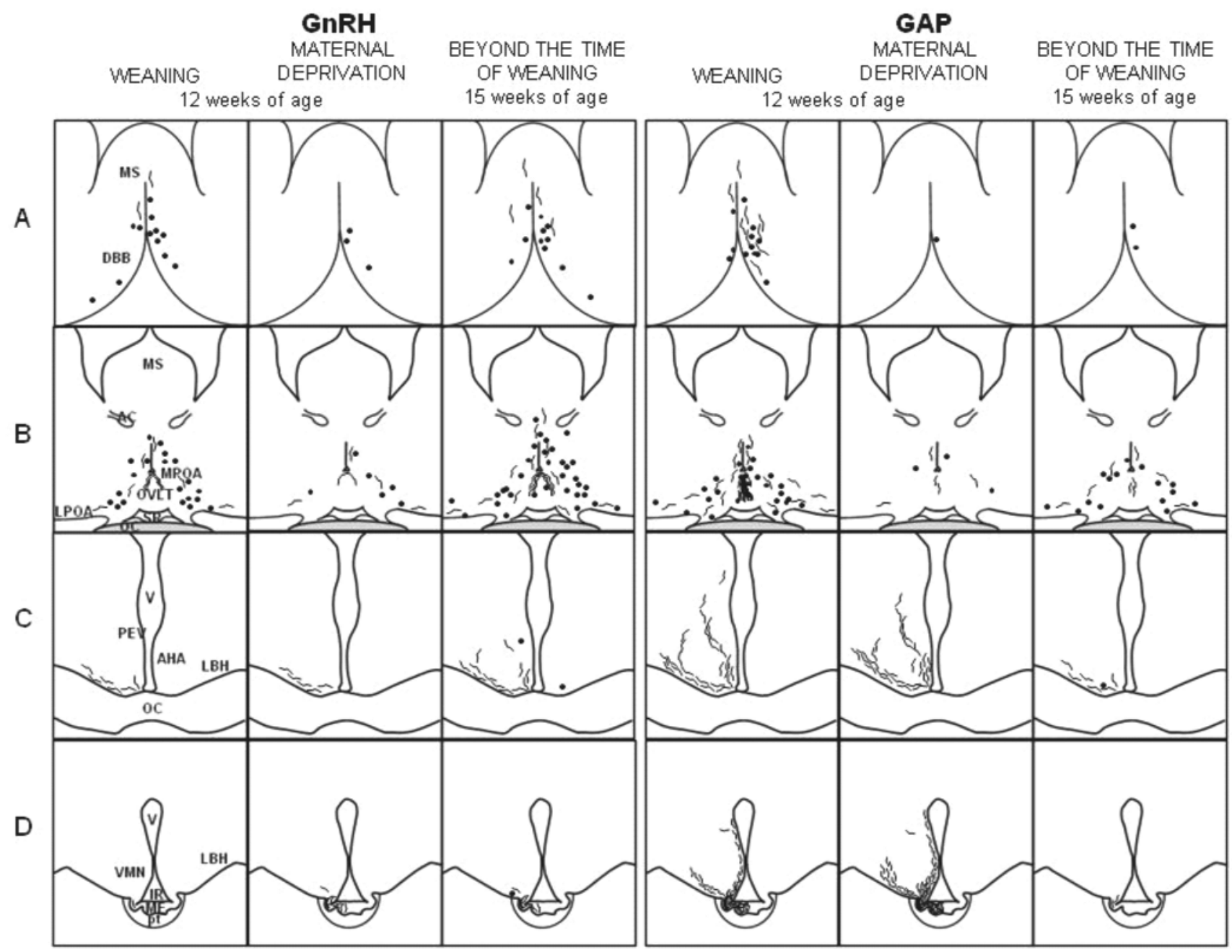

Fig. 1. Diagrammatic demonstration of distribution and density of GnRH-immunoreactive (ir) or GAP-ir nerve perikarya, fibers and terminals in preoptic area-hypothalamus of 12-week-old weanling and maternally deprived lambs and 15-week-old lambs beyond the time of weaning. Dots, perikarya; thin lines, fibers; solid lines, nerve terminals in the terminal fields. AC, anterior commissure; AHA, anterior hypothalamic area; DBB diagonal band of broca; IR, infundibular recess; LBH, lateral basal hypothalamus; LPOA, lateral preoptic area; MPOA, medial preoptic area; MS, medial septum; OC, optic chiasma; OVLT, organum vasculosum of the lamina terminalis; PEV, periventricular nucleus; pt, pars tuberalis of the anterior pituitary; SR, supraoptic recess; V, third ventricle of the brain; VMN, ventromedial nucleus.

mal) and (iii) 20 sections of the mediobasal hypothalamus (MBH) in the delineated area containing a structure of the median eminence extending from its rostral to caudal aspects ( 5 sections of the rostral aspect, 10 sections of the medial aspect and 5 sections of the caudal aspect per animal). Methodological details of the quantitative analyses had been described more precisely in our previous published study [14]. Briefly, the area fraction parameter was measured to define the percentage of the total area of the median eminence that exhibited specific staining. This parameter describes the dimension of the population of immunopositive for GnRH or GAP cross-sections of varicosities and/or nerve terminals. Quantitative analyses were performed under objective $10 \times(2$ fields of $0.3286 \mathrm{~mm}^{2}$ measured in each section) using a mechanical threshold function to select a range of values that were optically identified positive for staining.

The quantitative measurements of area fraction for ir $\mathrm{GnRH}$ or GAP taken from each section for each median eminence were averaged to obtain a mean estimate for the median eminence of each animal. Then, the above mentioned mean data or the total number of perikarya counted for each medial POA were pooled to represent the individual groups. Thus, the data are reported as the mean of total number of perikarya or percentage of the total area that exhibited immunostaining according to group $\pm \mathrm{SEM}$. The effects of the maternal deprivation on the factors studied were assessed by the Student's t-test, using the Statistica 6.0 PL software (StatSoft Inc., Tulsa, OK, USA).

\section{Results}

The GnRH-ir and GAP-ir perikarya in the DBB were more numerous in weanlings in comparison with maternally deprived lambs. The fibers ir for $\mathrm{GnRH}$ or GAP in the DBB and medial septum were not detected in maternally deprived lambs. In lambs beyond the time of weaning, the nerve elements ir for GnRH were numerous in contrast to the scarce GAP-ir ones (Figs 1A, 2). 


\begin{tabular}{|c|c|c|c|c|}
\hline \multicolumn{2}{|c|}{$\begin{array}{l}\text { NERVE } \\
\text { PERIKARYA }\end{array}$} & \multicolumn{3}{|c|}{$\begin{array}{c}\text { MATERNAL BEYOND THE TIME } \\
\text { WEANING DEPRIVATION OF WEANING }\end{array}$} \\
\hline \multirow[b]{2}{*}{ DBB } & Ir tor & $\mathrm{H}$ & $\downarrow$ & $\uparrow$ \\
\hline & GAP & $\mathrm{H}$ & $\downarrow$ & $=$ \\
\hline \multirow[t]{2}{*}{ MPOA } & GnRH & $\mathrm{L}$ & $\downarrow$ & 4 \\
\hline & GAP & L & ע & $\boldsymbol{I}$ \\
\hline \multirow{2}{*}{ OVLT } & GnRH & $x$ & $x$ & L \\
\hline & GAP & $\mathrm{H}$ & $\ddot{x}$ & $x$ \\
\hline \multirow[t]{2}{*}{ AHA } & $\mathrm{GnRH}$ & $x$ & $x$ & L \\
\hline & GAP & $x$ & $x$ & L \\
\hline \multirow{2}{*}{ MBH } & $\mathrm{GnRH}$ & $x$ & $x$ & $L$ \\
\hline & GAP & $x$ & $x$ & $x$ \\
\hline \multicolumn{5}{|c|}{ FIBERS } \\
\hline & ir for & & & \\
\hline \multirow{2}{*}{ DBB } & GnRH & $L$ & 胥 & $\mathrm{H}$ \\
\hline & GAP & $\mathrm{H}$ & $x$ & $x$ \\
\hline \multirow[t]{2}{*}{ MPOA } & GnRH & L & 」. & $A$ \\
\hline & GAP & $\mathrm{H}$ & & $\tau$ \\
\hline \multirow{2}{*}{ OVLT } & $\mathrm{GnRH}$ & $\otimes$ & $x$ & L \\
\hline & GAP & $\mathrm{H}$ & & $A$ \\
\hline \multirow{2}{*}{$\mathrm{AHA}$} & $\mathrm{GnRH}$ & $\mathbf{L}$ & $=$ & $\uparrow$ \\
\hline & GAP & $\overline{\mathrm{H}}$ & & \\
\hline \multirow{2}{*}{ MBH } & GnRH & $x$ & $L$ & $=$ \\
\hline & GAP & $\mathrm{H}$ & $\uparrow$ & $x$ \\
\hline \multirow[t]{2}{*}{ ME } & GnRH & 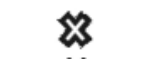 & L & $=$ \\
\hline & GAP & $\mathrm{H}$ & $=$ & \\
\hline \multicolumn{5}{|c|}{$\begin{array}{l}\text { TERMINALS } \\
\text { ir for }\end{array}$} \\
\hline \multirow{2}{*}{ OVLT } & $\mathrm{GnRH}$ & L & ฟ & $\uparrow$ \\
\hline & GAP & $\mathrm{H}$ & $x$ & L \\
\hline \multirow[t]{2}{*}{ ME } & GnRH & $L$ & $\hat{t}$ & $=$ \\
\hline & GAP & $\mathrm{H}$ & 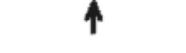 & \\
\hline \multirow[t]{2}{*}{ PS } & $\mathrm{GnRH}$ & $x$ & $\underline{x}$ & X \\
\hline & GAP & $\mathrm{H}$ & & $\leadsto$ \\
\hline
\end{tabular}

Fig. 2. The schematic comparison of distribution of GnRHimmunoreactive (ir) and GAP-ir nerve elements in the preoptic area-hypothalamus of 12-week old weanling and maternally deprived lambs and 15-week-old lambs beyond the time of weaning. L, H, =: low, high, similar immunoreaction; $\uparrow, \downarrow$ : increase, decrease in the immunoreaction; $x$, lack of immunoreaction. AHA, anterior hypothalamic area; DBB diagonal band of broca; $\mathrm{MBH}$, mediobasal hypothalamus; ME, median eminence; MPOA, medial preoptic area; OVLT, organum vasculosum of the lamina terminalis; PS, pituitary stalk.

The optically detected GnRH-ir and GAP-ir perikarya were generally scarce in the POA-hypothalamus of maternally deprived lambs in contrast to more numerous perikarya in weanlings and lambs beyond the time of weaning (Figs 1B-D, 2, 3). The total number of perikarya ir for GnRH or GAP in the medial POA was lower in maternally deprived lambs compared with weanling and weaned lambs $(p<0.05$; Fig. $4 \mathrm{~A}$ ). The changes in the population of optically detected GnRH-ir or GAP-ir fibers in the POA-hypothalamus were the same as that of cell bodies (Figs 1B-C, 2). They were almost undetectable in the medial POA in maternally deprived lambs (Figs 1B, 3). The GAPir fibers in the medial POA were, in contrast to GnRHir fibers, numerous in weanlings (Figs 1B, 2). In these lambs, the GAP-ir nerve elements were abundant within organum vasculosum of the lamina terminalis (OVLT) dorsal and midportions, whereas the nerve fibers and terminals ir for GnRH formed a narrow plexus within the dorsal and lateral portion of this organ, the terminal field of GnRH neurons (Fig. 1B). In maternally deprived lambs, the OVLT and its vicinity in the lateral wall of third ventricle of remained almost devoid of any labeling for GnRH and GAP. In lambs beyond the time of weaning, the GnRH-ir nerve elements were abundant within the dorsal and lateral portion of OVLT in contrast to scarce nerve fibers ir for GAP within midportions (Figs 1B, 2, 3).

We investigated two main tracts of GnRH fibers, i.e. axons of perikarya of origin in the medial POA and anterior and lateral hypothalamus, terminated in the median eminence. One ventrolateral, which contains the majority of fibers leaving the POA, and the other periventricular, originated from the perikarya located more dorsally in the POA and/or medial septum. The GAP-ir fibers of the ventrolateral pathway were, in contrast to $\mathrm{GnRH}$-ir fibers, similarly numerous in weanlings and maternally deprived lambs and scarce in lambs beyond the time of weaning (Figs 1C, 2). In contrast to GnRH-ir fibers, The GAP-ir fibers of the periventricular pathway were detected along the lateral walls of the supraoptic recess and third ventricle in the AHA in both groups (Figs 1C, 2). The GAP-ir fibers showed a preferential orientation toward the infundibular nucleus within the periventricular pathway joined by the ventrolateral trajectory in the $\mathrm{MBH}$ (Fig. 1D). The ir GAP was abundant in the nerve fibers and terminals in the both zona externa and interna of median eminence of weanling and maternally deprived lambs in contrast to lambs beyond the time of weaning (Figs 1D, 2, 3). The GAP-ir fibers contributed to the dense plexuses detected in the infundibular nucleus (Fig. 1D). In contrast to ir GAP, the GnRH-ir nerve elements were detectable mainly in the zona externa of median eminence and were more numerous in lambs after maternal deprivation and beyond the time of weaning in comparison with weanlings (Figs 1D, 2, 4B). The percentage of the area occupied by ir GAP in the median eminence was similarly high in weanlings and maternally deprived lambs compared to the low 


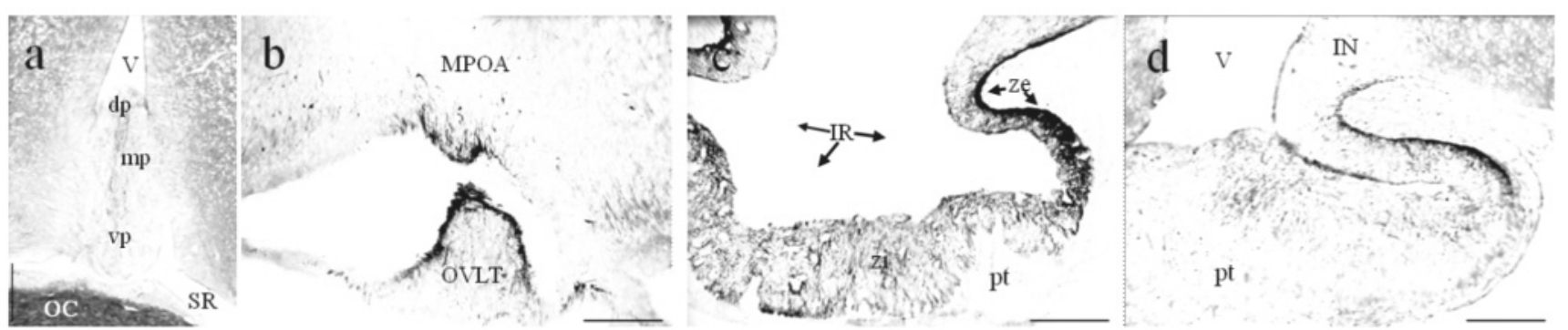

Fig. 3. The nerve elements immunoreactive for GnRH in the medial preoptic area $(\mathbf{a}, \mathbf{b})$ and for GAP in the medial aspect of the median eminence $(\mathbf{c}, \mathbf{d})$ in the representative 12-week-old maternally deprived lamb $(\mathbf{a}, \mathbf{c})$ and 15 -week-old lamb beyond the time of weaning $(\mathbf{b}$, d). Calibration bars $=500 \mu \mathrm{m}$; IR, infundibular recess; MPOA, medial preoptic area; OC, optic chiasma; OVLT, organum vasculosum of the lamina terminalis (dp, mp, vp - dorsal, medial, ventral part); pt, pars tuberalis of the anterior pituitary; SR, supraoptic recess; V, third ventricle of the brain; ze, zona externa; zi, zona interna.
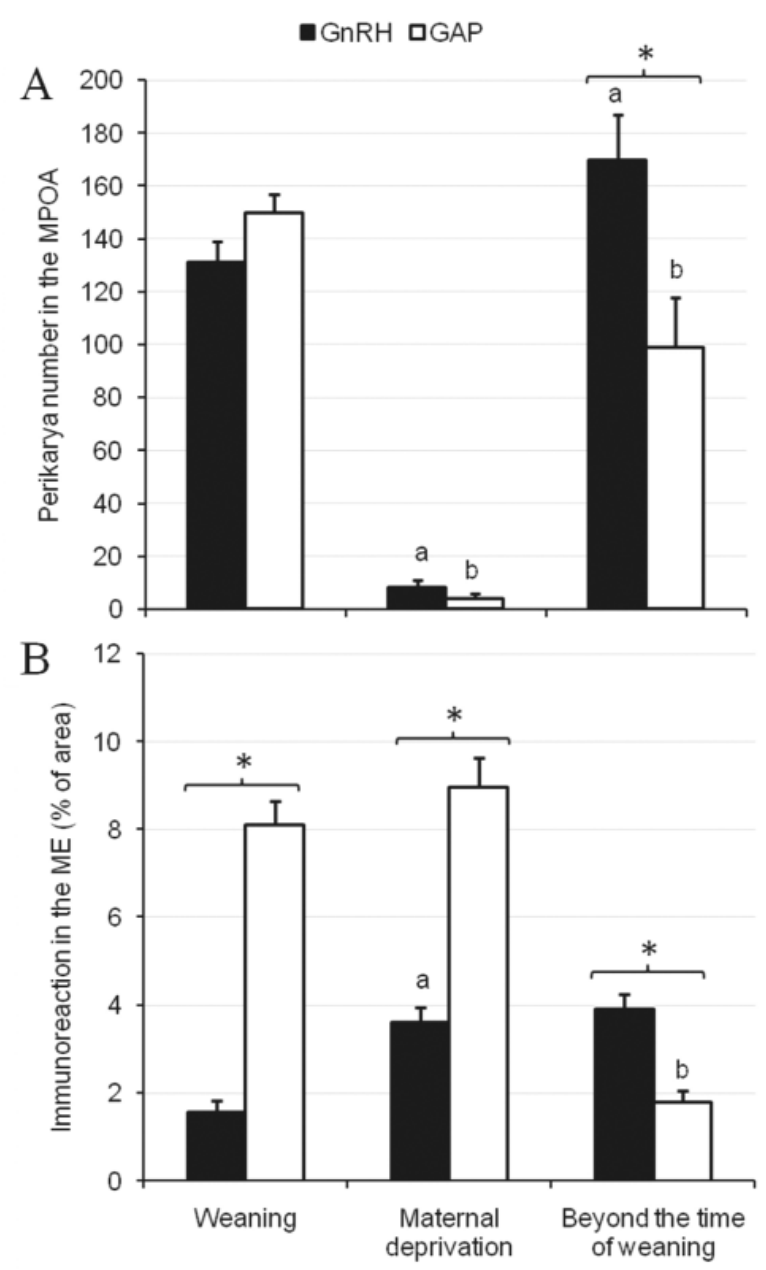

12 weeks of age

Fig. 4. The total number of perikarya immunoreactive (ir) for $\mathrm{GnRH}$ or GAP in the medial preoptic area (MPOA) (A). The percentage of the median eminence (ME) total area (area fraction) occupied by the GnRH-ir or GAP-ir nerve fibers and terminals (B) in 12-week old weanling and maternally deprived lambs and 15week-old lambs beyond the time of weaning. Values are mean \pm SEM (for the 12-week old sheep $\mathrm{n}=3$, for the 15 -week-old sheep $\mathrm{n}=4)$; ${ }^{\mathrm{a}} \mathrm{P}<0.05$ (GnRH, black bars), ${ }^{\mathrm{b}} \mathrm{p}<0.05$ (GAP, white bars), ${ }^{*} \mathrm{p}<0.05$ (GnRH versus GAP).

percentage in lambs beyond the time of weaning $(\mathrm{p}<0.05$; Fig. 4B). In contrast to ir GAP, the percentage of the area occupied by ir GnRH in the median eminence was low in weanlings compared to the similarly greater percentage in the remaining groups $(p<0.05$; Fig. 4B). In the pituitary stalk, nerve fibers and terminals ir for GAP were abundant in weanling and maternally deprived lambs and organized with this same pattern as in adults, whereas ir GnRH was undetectable.

\section{Discussion}

In mammals, the effect of maternal deprivation or other stressful situation on the dynamics in the intraneuronal locations involved in the processing of GnRH during the transition period between infancy and prepuberty is described for the first time. First, it should be mentioned that however GnRH and GAP are processed from the same precursor, they can present the differentiated posttranslational pattern of distribution in the perikarya, as well as nerve fibers and terminals [11]. The differences observed between the distribution of ir GnRH and GAP are due to their potentially different catabolism, heightened axonal transportation and/or terminal release. The processing of proGnRH to biologically active peptides, both the GnRH and GAP, begins in the cell soma and then progresses in secretory granules during axonal transport to the nerve terminals, where the proteolytic cleavage products are accumulated and released. Thus, in the perikarya we can find preproGnRH, proGnRH, GnRH and/or GAP, whereas in the nerve terminals we can recognize GnRH and GAP (the storage forms within the secretory vesicles) and some lower molecular weight GAP-like peptides according to the current neurosecretory activity of GnRH neurons [11,24-29].

The study demonstrates that the maternal deprivation causes the depletion of the GnRH in preoptic perikarya and the potential increase in the tempo of its axonal transport, since a scarce nerve fibers in the 
POA-hypothalamus and elevated accumulation of $\mathrm{GnRH}$ in the nerve terminals of the median eminence were observed. Comparable situation for ir GnRH was previously observed during the second half of prenatal life [30], youth and adulthood [31]. As axonal transport and accumulation in the median eminence increased, the perikarya storage decreased below the sensitivity treshold and colchicine injections are required for labeling GnRH perikarya [30]. Similar results of GnRH distribution and concentration, analyzed by radioimmunoassay and/or immunohistochemistry in the POA-hypothalamus, were observed in the anoestrous ewes submitted to prolonged [32] or long-term [33] stressful stimulation. In the present study, at the prepuberty inauguration the increase in the biosynthesis and terminal storage of GnRH is suggested. This suggestion arises from the observations of the more numerous perikarya ir for $\mathrm{GnRH}$ present in the POA of lambs beyond the time of weaning and elevated accumulation of GnRH in the nerve terminals of the median eminence in maternally deprived and weaned lambs. It was previously found for the infantile period, that GnRH plays a role in the development of hypophyseal gonadotrophic cells population and intrahypophyseal regulation of gonadotrophic hormones processing [34]. Therefore we suggested that the rupture of the young -mother contact, which seems a psychosomatic event important for neuroendocrine ontogeny, decreases the gonadotroph population secretory activity [14] in the pattern observed at the beginning of prepuberty [12] due to an attenuated release of GnRH to the hypothalamo-hypophyseal portal circulation of an offspring. Altogether, maternal deprivation affects the gonadotrophic axis activity on the level of the GnRH nerve perikarya, fibers and terminals in the POA-hypothalamus in the infantile female sheep. This effect involves intraneuronal locations which result in the greater terminal storage of decapeptide observed beyond the time of weaning, i.e. at the beginning of prepuberty. This finding suggests that the psychosomatic effects of weaning, which take part in the natural mechanisms of transition from the infantile to prepubertal period of ontogeny, may play a role in the timing of the maturational regulation of the gonadotrophic axis.

The changes in preoptic-hypothalamic GAP in maternally deprived lambs in comparison with weanlings, suggest an axonal transport acceleration and terminal release beginning in the median eminence. Later, beyond the time of weaning, the increase in the synthesis rate and accumulation of GAP in the preoptic perikarya and acute depletion due to probable terminal release and/or higher catabolism in the median eminence were observed. Given the changes in preoptic-hypothalamic GnRH, the finding of comparable abundant ir GAP in the median eminence of weanlings and maternally deprived lambs suggests that maternal deprivation enhanced the accumulation of $\mathrm{GnRH}$ in the median eminence, as was observed, due to an increase in the rate of GnRH maturation from pro$\mathrm{GnRH}$. This was probably accompanied by the release of GAP to the hypothalamic-hypophyseal portal circulation. Moreover, the comparable elevated accumulation of GAP in the median eminence of weanling and peripubertal lambs suggests its neuroendocrine importance during both postnatal transitional periods, the infantile/prepubertal and peripubertal [11]. However, the hypophysiotrophic functions of GAP in sheep are puzzling [35] and its physiological role in mammals is still not understood, thus the neuroendocrine mechanisms implicated must yet be determined. Moreover, the effect of stressful situations on the GAP in the mammalian POA-hypothalamus has not been investigated at all and this subject requires additional studies.

In conclusion, the weaning period is not static but shifts for the postnatal development of gonadotrophic hypophysiotrophic functions. Such psychosomatic events as the rupture of the young-mother contact affect the GnRH and GAP neurobiology in the POAhypothalamus of an offspring undergoing the neuroendocrine transition from the infantile to prepubertal period. The effect of maternal deprivation on the gonadotrophic axis in the weanling lambs involves the increase in the $\mathrm{GnRH}$ maturation from proGnRH and terminal accumulation in the median eminence. It reflects the maturational increase from the low infantile terminal storage of $\mathrm{GnRH}$ to the high peripubertal one.

Acknowledgments: The authors are grateful to the Mrs. Ewa Skrzeczyńska for technical assistance and will to thank Dr M.D. Culler (IPSEN, Milford, Massachusetts, USA) for the rabbit antirat GAP serum. This study was supported by the Polish Committee for Scientific Research, grant no. 6 PO6D 00820.

\section{References}

[ 1] Kinder JE, Bergfeld EG, Wehrman ME, Peters KE, Kojima FN. Endocrine basis for puberty in heifers and ewes. J Reprod Fertil Suppl. 1995;49:393-407.

[2] Moguilevsky JA, Wuttke W. Changes in the control of gonadotrophin secretion by neurotransmitters during sexual development in rats. Exp Clin Endocrinol Diabetes. 2001; 109:188-195.

[3] Terasawa E, Fernandez DL. Neurobiological mechanisms of the onset of puberty in primates. Endocrine Rev. 2001;22:111-151.

[4] Veldhuis JD, Roemmich JN, Richmond EJ, Bowers CY. Somatotropic and gonadotropic axes linkages in infancy, childhood, and the puberty-adult transition. Endocrine Rev. 2006;27:101-140.

[ 5] Seeburg PH, Adelman JP. Characterization of cDNA for precursor of human luteinizing hormone releasing hormone. Nature. 1984;311:666-668.

[ 6] Nikolics K, Mason AJ, Szonyi E, Ramachandran J, Seeburg H. A prolactin-inhibiting factor within the precursor for human gonadotropin-releasing hormone. Nature. 1985;316: 511-517. 
[ 7] Phillips HS, Nikolics K, Branton D, Seeburg PH. Immunocytochemical localization in rat brain of a prolactin releaseinhibiting sequence of gonadotropin-releasing hormone prohormone. Nature. 1985;316:542-545.

[ 8] Song T, Nikolics K, Seeburg PH, Goldsmith PC. GnRH-prohormone-containing neurons in the primate brain: immunostaining for the GnRH-associated peptide. Peptides. 1987;8: 335-346.

[ 9] Clark IJ, Cummins JT, Karsch FJ, Seeburg PH, Nikolics K. GnRH-associated peptide (GAP) is cosecreted with GnRH into the hypophyseal portal blood of ovariectomized sheep. Biochem Biophys Res Commun. 1987;143:665-671.

[10] Sarkar DK, Mitsugi N. Correlative changes of the gonadotropin-releasing hormone and gonadotropin-releasinghormone-associated peptide immunoreactivities in the pituitary portal plasma in female rats. Neuroendocrinology. 1990; $52: 15-21$

[11] Wańkowska M, Polkowska, J. Gonadotrophin-releasing hormone and GnRH-associated peptide neurobiology from the rearing period until puberty in the ewe. J Chem Neuroanat. 2009;38:9-19.

[12] Wańkowska M, Polkowska J. The postnatal ontogeny of gonadotroph cells in the female sheep. Developmental patterns of synthesis, storage and release of gonadotrophic hormones. J Chem Neuroanat. 2006;31:130-138.

[13] Wańkowska M, Romanowicz K, Polkowska J. The neuroendocrine events during the ovine growth-promoted maturation: the developmental importance of hypophysiotrophic action of somatostatin in ewes. Anim Reprod Sci. 2008;109:146-160.

[14] Wańkowska M, Starzec A, Counis R, Polkowska J. Effects of maternal deprivation on the adrenocorticotrophic and gonadotrophic axes in the hypothalamo-pituitary unit of preweanling female sheep: the histomorphometric approach. $J$ Chem Neuroanat. 2006;31:51-58.

[15] Marti O, Armario A. Anterior pituitary response to stress: time-related changes and adaptation. Semin Reprod Endocrinol. 1997;15:37-45.

[16] Schmidt M, Okimoto DK, Dent GW, Gordon MK, Levine S. Maternal regulation of the hypothalamic-pituitary-adrenal axis in the 20-day-old rat: consequences of laboratory weaning. J Neuroendocrinol. 2002;14:450-457.

[17] Napolitano F, Annicchiarico G, Caroprese M, De Rosa G, Taibi L, Sevi A. Lambs prevented from suckling their mothers display behavioral, immune and endocrine disturbances. Physiol Behav. 2003;78:81-89.

[18] Barry J, Dubois MP, Poulain P. LRF producing cells of the mammalian hypothalamus a fluorescent antibody study. $Z$ Zellforsch Mikrosk Anat. 1973;146:351-366.

[19] Dubois MP, Barry J. Répartition comparée de trois neurofacteurs hypotalamiques LHRH, SRIF et neurophysine dans l'hypothalamus et l'eminence médiane: étude en immunofluorescence. Annee Endocrinol. 1974;35:663-664.

[20] Culler MD, Negro-Villar A. Development of specific antisera and a radioimmunoassay procedure for the gonadotropinreleasing hormone associated peptide (GAP) of the LHRH prohormone. Brain Res Bull. 1986;17:219-223.

[21] Sar M, Culler MD, McGimsey WC, Negro-Villar A. Immunocytochemical localization of the gonadotropin-releasing-hormone-associated peptide of the LHRH precursor. Neuroendocrinology. 1987;45:172-175.
[22] Liposits Z, Sétáló G, Flérko B. Application of the silver-gold intensified 3, 3'-diaminobenzidine chromogen to the light and electron microscopic detection of the luteinizing hormonereleasing hormone system in the rat brain. Neuroscience. 1984;13:513-525.

[23] Welento J, Szteyn S, Milart Z. Observations on the stereotaxic configuration of the hypothalamus nuclei in the sheep. Anat Anz. 1969;124:1-27.

[24] Ronnekleiv OK, Adelman JP, Weber E, Herbert E, Kelly MJ. Immunohistochemical demonstration of proGnRH and GnRH in the preoptic-basal hypothalamus of the primate. Neuroendocrinology. 1987;45:518-521.

[25] Rubin BS, King JC, Millar RP, Seeburg PH, Arimura A. Processing of luteinizing hormone-releasing hormone precursor in rat neurons. Endocrinology. 1987;121:305-309.

[26] Wetsel WC, Culler MD, Johnston CA, Negro-Vilar A. Processing of the luteinizing hormone-releasing hormone precursor in the preoptic area and hypothalamus. Mol Endocrinol. 1988;2:22-31.

[27] Ronnekleiv OK, Naylor BR, Bond CT, Adelman JP. Combined immunohistochemistry for gonadotropin-releasing hormone $(\mathrm{GnRH})$ and pro-GnRH, and in situ hybridization for $\mathrm{GnRH}$ messenger ribonucleic acid in rat brain. Mol Endocrinol. 1989;3:363-371.

[28] Kelly MJ, Garrett J, Bosch MA et al. Effects of ovariectomy on GnRH mRNA, proGnRH and GnRH levels in the preoptic hypothalamus of the female rat. Neuroendocrinology. 1989; 49:88-97.

[29] Silverman AJ, Witkin JW, Millar RP. Light and electron microscopic immunocytochemical analysis of antibodies directed against $\mathrm{GnRH}$ and its precursor in hypothalamic neurons. J Histochem Cytochem. 1990;38:803-813.

[30] Caldani M, Antoine M, Batailler M, Duittoz A. Ontogeny of GnRH systems. J Reprod Fertil Suppl. 1995;49:147-162.

[31] Caldani M, Batailler M, Thiery JC, Dubois MP. LHRHimmunoreactive structures in the sheep brain. Histochemistry. 1988;89:129-139.

[32] Przekop F, Polkowska J, Mateusiak K. The effect of prolonged stress on the hypothalamic luteinizing hormonereleasing hormone (LHRH) in the anoestrous ewe. Exp Clin Endocrinol. 1988;91:334-340.

[33] Polkowska J, Przekop F. Neuroendocrine responses to footshock stress in anestrous ewes. In: Kvetanski R, McCarty R, Axelrod J, ed. Stress-neuroendocrine and molecular approaches. Philadelphia, Conn: Gordon and Breach Science Publishers; 1992:467-472.

[34] Blake CA, Campbell GT, Mascagni F, Culler MD, Negro-Vilar A. Effects of injection of anti-luteinizing hormone (LH)-releasing hormone serum and anti-gonadotropin-releasing hormoneassociated peptide serum into neonatal rats on LH and folliclestimulating hormone cells. Biol Reprod. 1993;49: 965-971.

[35] Thomas GB, Cummins JT, Doughton BW, Griffin N, Millar RP, Milton RC. Gonadotropin-releasing hormone associated peptide (GAP) and putative processed GAP peptides do not release luteinizing hormone or follicle stimulating hormone or inhibit prolactin secretion in the sheep. Neuroendocrinology. 1988;48:342-350.

Submitted: 16 September, 2009 Accepted after reviews: 21 January, 2010 